\title{
MEMÓRIA E IDENTIDADE NA TESSITURA DO EU FEMININO EM DESPIDA, DE INÊS PEREIRA MACIEL.
}

\author{
Rhusily Reges da Silva Lira ${ }^{1}$ \\ Silvana Maria Pantoja dos Santos ${ }^{2}$
}

\begin{abstract}
RESUMO: Este trabalho tem por objetivo analisar a relação entre memória e identidade na representação da figura feminina na obra Despida, da escritora maranhense Inês Pereira Maciel. A relação entre memória e identidade perpassa pela condição do sujeito de retraçar episódios dispersos do seu passado, como uma tentativa de compreensão de si mesmo. Para tanto, os episódios compartilhados com os membros da família, os emblemas (fotografias, objetos da sala de estar, dos quartos, as flores do jardim), bem como os lugares de vivências individuais e coletivas, em constante interação com o meio, as pessoas e com a vida, são aspectos salutares na ressignificação do vivido do eu que se pronuncia. A pesquisa é qualitativa, fundamentada na visão de Maurice Halbwachs (2006), Eclea Bosi (2003), Joel Candau (2012), no que se refere à memória; para a construção da identidade feminina usamos o pensamento de Zinani (2006), Rocha-Coutinho (1994), dentre outros. A obra Despida engloba poemas que tratam de perdas, tristezas, mas, sobretudo dos afetos do eu lírico feminino em torno dos elementos constitutivos da sua condição de existência, perpassando por uma subjetividade que evidencia a condição de ser mulher.
\end{abstract}

PALAVRAS-CHAVE: Literatura; Memória; Figura Feminina.

\section{INTRODUÇÃO}

O presente trabalho objetiva analisar o processo de rememoração do eu lírico feminino na obra Despida, de Inês Pereira Maciel, a fim de se compreender como se dá a construção da identidade feminina. Para tanto, vale questionar: I) de que modo o eu-lírico se reconhece como sujeito social, a partir das suas relações com o grupo social ao qual pertence? II) como a ressignificação do passado ajuda na reconstrução da identidade feminina? Convém ressaltar que a força motriz de revolver o passado suscita a busca pela identidade, que implica autoconhecimento e superações, questões tão antigas quanto o próprio homem e tão atuais em tempos contemporâneos.

Inês Maciel é advogada e poeta. Atuante no cenário artístico-cultural da cidade de Caxias - MA, tem dado contribuições relevantes à cultura caxiense. Ocupa a cadeira de №18 da Academia Caxiense de Letras, atualmente tem se dedicado exclusivamente à vida literária.

\footnotetext{
${ }^{1}$ Graduanda do Curso de Letras Português da Universidade Estadual do Maranhão - Campus Timon. Email: rhusilyr@outlook.com.

2 Professora Doutora de Literaturas de Língua Portuguesa - UEMA/UESPI; E do mestrado acadêmico - UEMA/UESPI. Coordenadora do Grupo de Pesquisa Interdisciplinar em Literatura e Linguagem - LITERLI. Email: silvanapantoja3@gmail.com
} 
. A poeta tem outras obras conhecidas, dentre elas o romance Virna (2014), a coletânea de crônicas publicadas em periódicos sob o título Ramos do Tempo (2003) e a mais recente publicação, o livro de poemas Recôndito (2016).

A obra Despida foi publicada em 2008 e contempla diferentes temas, dentre eles a rememoração, na qual sobressai a saudade da infância, as lembranças da casa paterna com seus micros espaços, as relações amorosas, os vínculos familiares e a relação com o lugar/cidade.

Pesquisas envolvendo memória e identidade feminina tornaram-se significativas nos últimos anos, isso se justifica pelo interesse de se estudar o modo como a mulher compreende a si mesma, em meio à sociedade que a envolve. Segundo Candau, (2016, p.59) "A perda de memória é, portanto, uma perda de identidade". Assim, a memória é a composição fundamental, pois se entrelaça com o passado, presente e futuro, resultando na formação da identidade do sujeito.

Por sua vez, a identidade se constitui a partir da interação com as práticas sociais, articuladas com vivências em tempos e espaços diferenciados. Zinani (2006) afirma que o sujeito como locus da contradição e a identidade como consciência formadora do individuo, fragmenta-se em inúmeras possibilidades, uma das quais é a relação de gênero. O gênero, então, constitui-se dentro de uma estrutura social, seguindo padrões pré-estabelecidos, em geral, fruto de discursos de poder, permeados por relações interpessoais. Essa força é visível no cotidiano de muitas mulheres que ainda vivem sob o teto de um regime Patriarcal.

Essa conjuntura tem gradativamente se modificada, graças à inserção da mulher no mercado de trabalho, desempenhando diferentes papeis. Tal inserção se deu por meio de muitas lutas por igualdade entre homem e mulher. Assim, a realidade que se vislumbra no contextual atual envolve um olhar retrospecto da mulher em torno de vivências tanto particulares, quanto coletivas, como forma não somente de reavaliar a sua condição de ser mulher, como também de afirmação da identidade feminina.

Assim, a relação entre memória e identidade é fundamental na constituição do sujeito, nesse caso, sujeito feminino, cuja condição está 
relacionada às práticas sociais, às mudanças, às raízes e também às rupturas que se interligam na formação da identidade.

\section{DESPIDA: A FIGURA FEMININA E A RELAÇÃO ENTRE MEMÓRIA E IDENTIDADE.}

A obra Despida, de Inês Pereira Maciel, é dividida em três partes: a primeira, sem título, composta por 44 poemas, traz reminiscências envolvendo diferentes enfoques, sendo que a cidade natal é que mais se sobressai, envolta por uma atmosfera de aconchego e proteção; a segunda, intitulada "Breves" contempla 4 poemas curtos que remetem a flashes de memória; a terceira, denominada "Álbum de Família", é constituída de 11 poemas mais longos, dedicados às relações familiares, que envolvem lembranças da infância até a vida adulta.

Como assevera Santos (2012, p. 364), a obra Despida é instigante a partir do título: "qual o corpo, a memória tem suas vestimentas. [...] Em Despida, o mundo de Inês torna-se público e num delicado desnudar, sem cerimônia, a intimidade dos espaços de memória vão se tornando visíveis". O título Despida também traz a ideia de uma poesia livre, sem adereços. Por meio de um arcabouço de imagens suaves e instigantes, o eu lírico revela a leveza de suas lembranças, regadas de alegrias, tristezas, perplexidades, anseios, como se pode constatar no poema Fagulhas.

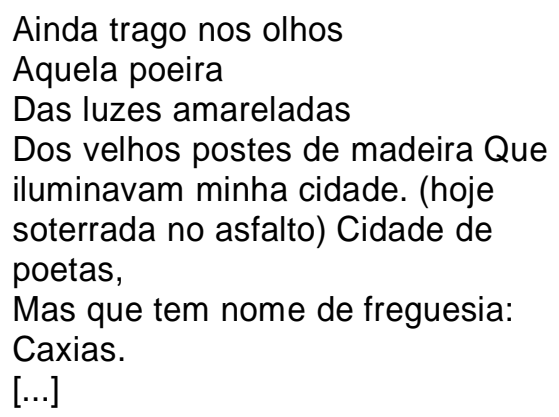

(MACIEL 2014,.17)

O nome fagulhas remete a faíscas, conversa com a construção do poema, pois as imagens são emitidas através de flashes, como o processo próprio da memória. Sendo um poema memorialístico, as imagens se precipitam como as faíscas que se desprendem das labaredas. O verso "ainda trago nos olhos" 
sugere a perplexidade do eu lírico diante de uma paisagem da cidade da infância, não mais possível, posto que "soterrada no asfalto". Estamos diante de um eu adulto que se reporta às lembranças de um tempo e contexto distanciados, sugeridas pelos advérbios "ainda" e "hoje", com isso, alterna o tempo e, por meio das reminiscências deixa aflorar os costumes, as brincadeiras, o clima nostálgico da cidade, dissolvidos na vivência tanto de si, quanto dos demais integrantes do lugar. Halbwachs assevera que

\begin{abstract}
Nossas lembranças permanecem coletivas e nos são lembradas por outros, ainda que se trate de eventos em que somente nós estivermos envolvidos e objetos que somente nós vimos. Isto acontece porque jamais estamos sós. É difícil encontrar lembranças que nos levem a um momento em que nossas sensações eram apenas reflexos dos objetos exteriores, em que não misturássemos nenhuma das imagens, nenhum dos pensamentos que nos ligavam a outras pessoas e aos grupos que nos rodeavam. (HALBWACHS, 2006, p.30-43)
\end{abstract}

O sujeito poético ao deslocar o nome da cidade em um único verso Caxias -, enseja a noção de pertencimento, que corrobora para a constituição de sua identidade, já que o lugar acolhe as marcas de referências do sujeito. Do mesmo modo, a casa paterna metonimicamente representada pelo casarão no poema Doce prisão contribui para o caráter identitário da mulher que se enuncia.

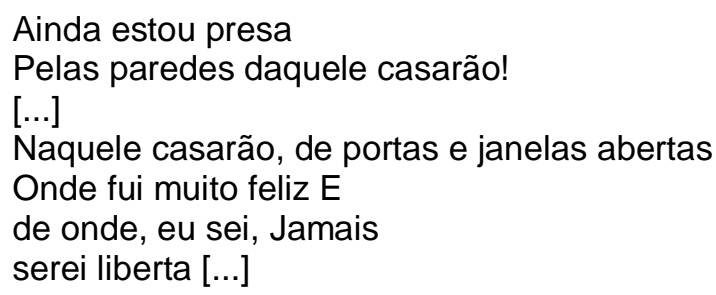

O seguimento "de portas e janelas abertas" remete à sensação de liberdade, contrastando com: "Onde fui muito feliz/ E de onde, eu sei/ jamais serei liberta!". O paradoxo confirma o sentido de prisão adocicada anunciada no título, no instante em que rompe com a ideia de um lugar que priva de liberdade. $\mathrm{O}$ casarão que acolhe as lembranças é, para o eu lírico, um espaço acolhedor. Esse espaço feliz é caracterizado por Bachelard (1993, p.19) como topoíliico, remete ao "elo afetivo entre a pessoa e o lugar ou ambiente físico".

A casa natal é uma casa habitada. Os valores de intimidade aí se dispersam, estabilizam-se, mal sofrem dialéticas. [...] A casa natal 
está fisicamente inserida em nós. Ela é um grupo de hábitos orgânicos. (BACHELARD. 1993, p.33)

O casarão, espaço habitado com todos os objetos e pessoas que o compõe, é fundamental para a constituição da identidade do eu poético da obra. O espaço torna-se doce, tanto pelo valor caracterizado pelos entes queridos, quanto pela segurança que o lar favorece. Segundo Zinani (2006, p.61), a vida na sociedade patriarcal era demarcada por dois espaços - o público e o privado, sendo o último caracterizado pelo lar sob o jugo paterno, cuja presença da mulher era marcada pela submissão.

A casa natal possui abrigos íntimos, que comportam memórias e devaneios diferentes. As lembranças da casa natal são visíveis em Despida, pelo olhar retrospecto da figura feminina que deixa transparecer os lugares ocupados nas relações familiares.

Portas e janelas do velho casarão fechadas...

Passos e sons que só os corações escutam... E na quietude do teu jardim, flores caladas,

Guardam a solidão... E também te buscam!

(MACIEL, 2014, p. 121)

A relação com a casa primigênia é fundamental para a construção da identidade do sujeito poético da obra Despida, pois a partir daquele "mundo" insere-se na vida - a casa natal como o primeiro espaço de sociabilidades atribui ao ser características identitárias. A casa da primeira infância, com seus sons particulares e passos familiarizados pela convivência diária, recolhe-se no tempo e se fecha sobre si mesma. Como assevera Santos (2012, p. 365), "Da casa materna, como concha, como útero, emana harmonia, acolhida e pleno amor".

Rocha-Coutinho (1994, p.45) enfatiza que "as características e capacidades atribuídas às mulheres não são inatas, mas sim habilidades desenvolvidas a partir de um aprendizado social". O poema Provinciana, que pode se articular com o título da obra, traz a voz feminina com uma afirmação de quem seja essa mulher que se desnuda.

Sou provinciana, sou como uma abelha,

E se assim sou, assim gosto de ser...

Sou rústica, sou da terra, sou cabreira,

Mas sou livre em minha forma de viver... 
Sou como a chuva que molha o campo

Sou como a jabuticaba, pau d' arco, jatobá

Sou como faísca passageira de um relâmpago,

Sou como um bicho, sou do mato, sou de lá...

Sou como uma nuvem que passa errante, Sobre um entrelaçado de vida abundante Onde a natureza e a poesia são tecelãs...

Mas trago nos olhos o piscar dos vaga-lumes $E$, entranhado na alma, eu guardo o perfume Das flores silvestres, no alvor das manhãs...

(MACIEL, p.41, 2014)

A autoafirmação do eu lírico demonstra que não se sente intimidado em se desnudar. A condição de ser "bicho do mato", provinciana, não a torna diminuída na sua condição de ser mulher. Estamos diante de uma mulher que se interioriza para compreender a si mesma, e se despe revelando o seu lugar de pertencimento. Ademais, ao tempo em que se situa no espaço provinciano, revela uma personalidade forte e determinada. Como afirma Santos:

\footnotetext{
O uso enfático do verbo "ser" reitera o universo interior desse eu feminino. Utilizando-se de elementos paradoxais da natureza, como relâmpago e paud'arco; jabuticaba e jatobá, desnuda uma realidade própria do ser mulher. (SANTOS, 2012, p. 362)
}

Assim, o eu lírico consegue quebrar o estereótipo que se tem da mulher: o de ser frágil e dependente. Quanto ao relâmpago, o eu-lírico mostra-se revestido de uma força, uma eletricidade que se anuncia já na abertura da obra.

O uso do verbo "ser" justifica-se pela necessidade que tem de se autonomear, comportamento que se encontra em sintonia com a memória. Como assevera Candau (2016), "Todo dever de memória passa em primeiro lugar pela restituição de nomes próprios". Assim, as afirmações do sujeito poético de "ser" confirmam a sua identidade.

No poema Sina, o sujeito poético escolhe o verbo esperar para traçar a configuração do destino da mulher da sociedade patriarcal. Esse verbo possui uma carga semântica de dependência, subserviência, que caracteriza a condição da mulher nessa conjuntura social:

\footnotetext{
Esperar o alimento

Esperar o uguento

Esperar o filho
}

Revista de Letras JUÇARA, Caxias - Maranhão, v. 02, n. 01, p. 102 - 111, jul. 2018|107 
[...]

Esperar o amor

Esperar o sossego

Esperar o silêncio

[...]

Esperar o gozo

Esperar o bálsamo

Esperar o consolo

Esperar o abraço

$[\ldots]$

(MACIEL, p.49-50, 2014)

"Esperar o alimento/Esperar o unguento/Esperar o filho", versos que remetem à espera do outro. Como nos diz Zinani (2006),

O eu-lírico manifesta seu papel de objeto, de Outro, ao se comportar de acordo com o estereótipo feminino, entretanto, não encontra na maternidade a sua autonomia, uma vez que essa função constitui uma carga, tanto por diminuir sua capacidade de trabalho como por coloca-la na dependência do homem em relação à proteção e à subsistência (ZINANI, 2006, p. 62-95)

Desse modo, notamos o sentimento de subserviência construído a partir de um comportamento que é atribuído às mulheres em relação aos homens, sobretudo em relação ao casamento, pois, quando a mulher casa a sociedade espera que logo engravide: "esperar o filho"; quem sustenta a casa é o marido, ou seja, a mulher a "esperar o alimento", visão em torno da mulher, imbuída de passividade em relação ao companheiro. Nesse caso, é pertinente associar à figura de Penélope (fazendo referência à Odisseia), metáfora da longa e angustiosa espera e que reforça a situação da passividade de sua situação de "esperar" alguma coisa (ZINANI).

As "Penélopes" permanecem desempenhando exatamente o mesmo papel, aguardando, reclusas, o retorno do homem que vai prover a sua existência. Essa maneira que as mulheres têm de entender a realidade reitera continuamente a inferioridade da posição feminina que é perpetuada por elas próprias. (ZINANI, 2006, p.96)

Propõe Zinani (2006) que o rompimento com as práticas tradicionais é imprescindível para que um novo sujeito que se redefine nas práticas sociais e discursivas se reconheça, isso envolve a experiência feminina. No poema Laço, o eu lírico se reinventa a partir da tomada de atitude, cuja construção discursiva dáse por meio da imagem do rompimento afetivo. 
Desfez-se o laço...

E nos teus abraços

Eu abraço

$O$ antigo mundo que desfaço,

A nostalgia que disfarço,

E velhos sonhos...

Que não mais enlaço!

(MACIEL, p.115, 2014)

O curto poema dialoga com a imagem que propõe: a da brevidade das relações, cuja alternância entre $o$ atado/desatado sugere a ideia de uma mulher determinada a romper com um modelo, que tem no casamento a sensação de solidez e segurança. Contudo, o eu-lírico ainda carrega certa cautela frente ao constructo social ao anunciar: "nostalgia que disfarço", logo rejeitada por ela, cuja dissimulação de sofrimento/saudade é algo também imposto à mulher. Isso remete ao pensamento de Candau ao afirmar:

(...) A paixão memorial pode revelar uma rejeição da representação que fazemos de nossa identidade atual, projetando no passado e, por vezes, ao mesmo tempo no futuro uma imagem do que gostaríamos de ter sido. (CANDAU, 2016, p.18)

Assim, o eu lírico feminino mostra-se emponderado ao enunciar " $E$ nos teus braços/ eu abraço/ o antigo mundo que desfaço", sugerindo que a nova perspectiva de vida poderá contribuir para a superação das dores do passado. Isso demonstra que essa mulher que se pronuncia tem sua vida emocional sob controle. Dessa forma, disposta a arremessar-se a uma nova relação, de forma despretensiosa.

\section{CONSIDERAÇÕES FINAIS}

Os textos literários produzidos por mulheres favorecem os estudos sobre a condição de ser mulher, a partir do próprio sujeito feminino, já que trazem uma percepção do mundo particular ao universo feminino, é o que acontece com a obra Despida, de Inês Pereira Maciel.

A obra é marcada pelo processo de rememoração do eu-lírico feminino em torno das lembranças da infância, das reminiscências da casa primigênia com seus compartimentos que acolhem e protegem -, dos afetos que giram em torno dos familiares e de amores perdidos. 
A memória estabelece fortes vínculos com as práticas sociais, já que memória individual está ancorada na memória coletiva, composta pelas relações que o sujeito estabelece com o grupo, especialmente, nas relações familiares. Em Despida as lembranças do eu-lírico são entrecortadas pela presença de pessoas marcadas pelo afeto, como a mãe, presença nuclear no universo do lar e o pai, que figura como imagem da ordem familiar. A herança da sociedade patriarcal é fator determinante nos valores e comportamentos, que acabam sendo incorporados à existência.

Em contrapartida, a voz feminina de Despida apresenta atitudes que sugerem rupturas com a visão social pré-estabelecida. Deixa entrever a condição ser mulher, por meio de sutilezas em que subjaz o empoderamento feminino ao atribuir-Ihe certa liberdade de se auto nominar, de deslizar entre o enlace/desenlace, cujos comportamentos convergem à formação identitária como podemos perceber no poema Provinciana um eu lírico que se autonomeia e aceita a sua condição e essa nomeação pode ser percebida como a efetivação da identidade.

Na obra Despida, o empoderamento à associado à identidade, se a entendermos como um meio pelo qual o eu lírico tem a possibilidade de agir como quer e de ser autonomear como quiser. Diante disso, não podemos pensar em identidade sem associarmos à memória, como afirma Candau (2016), "A perda da memória é a perda da identidade", pois a memória permite unir aquilo que fomos ao que somos e ao que seremos. No caso do eu lírico da obra Despida, a memória é o caminho para romper com os laços estabelecidos e para (re)construir a identidade.

\section{MEMORY AND IDENTITY IN THE FABRIC OF THE FEMININE SELF IN DESPIDA, BY INÊS PEREIRA MACIEL.}

ABSTRACT: This work aims to analyze the relation between memory and identity in the representation of the female figure in the work Despida, by the Maranese writer Inês Pereira Maciel. The relation between memory and identity runs through the condition of the subject to retract scattered episodes from his past, as an attempt to understand himself. In order to do so, episodes shared with family members, emblems (photographs, objects of the living room, bedrooms, garden flowers), as well as places of individual and collective experiences, in constant interaction with the environment, people and life are salutary aspects in the resignification of the lived of the self that is pronounced. The research is qualitative, based on the vision of Maurice Halbwachs (2006), Eclea Bosi (2003), Joel Candau (2012) and for the construction of feminine identity we use the thinking of Zinani (2006) and Rocha-Coutinho (1994), among others. The work Despida includes poems that deal with loss, sadness, but above all the affections of the female 
lyrical I around the constituent elements of its condition of existence, permeating a subjectivity that shows the condition of being a woman.

KEYWORDS: Literature; Memory; Female figure.

\section{REFERÊNCIAS}

BACHELARD, Gaston. A poética do espaço. São Paulo. Martins Fontes, 1993. CANDAU, Joel. Memória e identidade. $1^{1}$.ed. São Paulo: Contexto, 2016.

HALBWACHS, Maurice. A memória coletiva. São Paulo: Centauro, 2003.

MACIEL, Inês Pereira. Despida. 2ª edição. Caxias: Gráfica \& Editora JM Ltda, 2014.

ROCHA-COUTINHO, Maria Lúcia. Tecendo por trás dos panos: a mulher brasileira nas relações familiares. Rio de Janeiro: Rocco, 1994.

SANTOS, Silvana Maria Pantoja dos. Identidade e Memória ou As fraturas do tempo em Despida, de Inês Pereira Maciel. In: MENDES MACÊDO DE, A; ARAÚJO SILVA DA, J. (Orgs) Diálogos de gênero e representações literárias. Teresina: EDUFPI, 2012, p. 359-372

ZINANI, Cecil Jeanine Albert. Literatura e gênero: a construção da identidade feminina. Caxias do Sul, Rs. Educs, 2006.

Trajetórias de literatura e gênero: territórios reinventados. Caxias do Sul, Rs. Educs, 2016

Data da submissão: $30 / 04 / 2018$

Data da aprovação: 26/04/2018 